\title{
Otras enfermedades periodontales. II: Lesiones endo-periodontales y condiciones y/o deformidades del desarrollo o adquiridas
}

\author{
SANZ-SÁNCHEZ I* \\ BASCONES-MARTÍNEZ A**
}

\begin{abstract}
Sanz-Sánchez I, Bascones-Martínez A. Otras enfermedades periodontales. II: Lesiones endo-periodontales y condiciones y/o deformidades del desarrollo o adquiridas. Av Periodon Implantol. 2008; 20, 1:67-77.
\end{abstract}

\begin{abstract}
RESUIMEN
Introducción: En el último workshop en periodoncia, llevado a cabo por la asociación americana de periodoncia en 1999, se añadieron, entre otros, un grupo de lesiones y de condiciones que, por su prevalencia y por la imposibilidad de ser clasificados en otros grupos, debían ser tenidos en cuenta y analizados de un modo distinto para establecer un correcto diagnóstico diferencial. Los objetivos de este trabajo son: a) Conocer el impacto de las lesiones endoperiodontales y ser capaces de realizar un correcto diagnóstico diferencial para poner en marcha la estrategia terapéutica oportuna; b) Conocer las condiciones y deformidades que se pueden dar en los tejidos periodontales.

Material, métodos y resultados: Para la realización de este trabajo se han analizado 17 artículos publicados en revistas científicas con índice de impacto internacional y otras de ámbito nacional. Para la búsqueda se han empleado la base de datos MEDLINE y Cochrane.
\end{abstract}

\section{PALABRAS CLAVE}

World Workshop, endo-perio lesions, periodontitis, gingival recession, queratinized gingiva, trauma from occlusion.

Fecha de recepción: Noviembre 2007.

Aceptado para publicación: Diciembre 2007.

\section{INTRODUCCIÓN}

Las clasificaciones de las enfermedades periodontales han ido cambiando a lo largo de las últimas décadas. Se ha tratado de buscar un consenso que pusiese de acuerdo a las distintas asociaciones mundiales, pero esto no ha sucedido y en su lugar han ido surgiendo nuevas clasificaciones que trataran de corregir los defectos de las anteriores. En la última clasificación, pro- puesta por la asociación americana de periodoncia $\left(2^{\circ}\right.$ World Workshop) se incluyeron, entre otros, las lesiones endo-periodontales y las condiciones y/o deformidades del desarrollo o adquiridas. Este hecho se debió principalmente a que existían una serie de situaciones clínicas que no podían ser encuadradas dentro de las periodontitis del adulto, de comienzo temprano, necrotizantes o como manifestaciones de enfermedades sistémicas $(1,2,3,4)$.

\footnotetext{
* Alumno Máster en Ciencias Odontológicas y Periodoncia e Implantes. Facultad de Odontología. Universidad Complutense de Madrid.

** Catedrático de Medicina Bucal y Periodoncia. Facultad de Odontología UCM. Director Máster en Periodoncia e Implantes (UCM).
} 
Los objetivos de este trabajo son:

- Conocer las lesiones endo-periodontales para poder realizar un correcto diagnóstico diferencial y llevar a cabo la estrategia terapéutica oportuna.

- Conocer las distintas deformidades y condiciones periodontales desarrolladas y adquiridas con el fin de distinguirlas de las enfermedades periodontales clásicas.

\section{MATERIAL Y MÉTODOS}

Para la realización de esta revisión hemos analizado 17 artículos publicados en revistas científicas con índice de impacto internacional y en otras revistas nacionales y libros de texto.

Para la búsqueda hemos empleado las bases de datos MEDLINE en www.pubmed.com y Cochrane. En una primera búsqueda se encontraron numerosos artículos, para lo que se decidió establecer los siguientes criterios:

- Idioma: inglés.

- Dental journals.

- Palabras clave:World Workshop, endo-perio lesions, periodontitis, gingival recession, queratinized gingiva, trauma from occlusion.

\section{DISCUSIÓN}

\section{PERIODONTITIS ASOCIADAS A LESIONES ENDODÓNTICAS}

Existen vías de comunicación entre el periodonto y la pulpa a través del foramen apical y de los canales laterales, lo que permite el paso de agentes nocivos de una zona a la otra cuando alguno de los dos, o ambos, se encuentran alterados. También pueden ocurrir procesos degenerativos en los dientes, o incluso nuestro propio tratamiento periodontal, que conlleven a la exposición de los túbulos dentinarios, lo que supone una nueva vía de comunicación entre ambas estructuras anatómicas.

La estrecha relación que existe entre el periodonto y la pulpa dificulta en muchas ocasiones el diagnóstico diferencial de las lesiones que tienen lugar en ambos. $\mathrm{Si}$ el proceso inflamatorio de los tejidos periodontales es el resultado de agentes nocivos presentes en el sistema de conductos del diente hablamos de una lesión endodóntica que suele estar confinada en la zona api$\mathrm{cal}$. Si el proceso inflamatorio en los tejidos periodon- tales es debido a la acumulación de placa bacteriana en las superficies dentarias externas se trata de una lesión periodontal que suele manifestarse más a nivel marginal. Si el diente se encuentra afectado por ambas lesiones hablaríamos de una lesión endo-periodontal verdadera.

Además, las fracturas radiculares y las perforaciones de raíz (iatrogénicas) e pueden asociar con procesos inflamatorios en el periodonto de naturaleza similar a los que ocurren en las enfermedades de la pulpa y en la enfermedad periodontal. También se hará una mención a las reabsorciones radiculares.

\section{INFLUENCIA DE LAS CONDICIONES PATOLÓGICAS DE LA PULPA SOBRE EL PERIODONTO}

Los procesos patológicos que afectan a la pulpa, como ocurre con la caries dental, se suceden en distintas fases. En un primer lugar acontecen cambios inflamatorios en la misma, y mientras se mantenga vital, la afectación periodontal es mínima, pues como mucho podremos ver un engrosamiento del espacio periodontal o una lámina dura periapical difuminada.

Sin embargo, a medida que la afectación pulpar avan$\mathrm{za}$, los cambios que se producen a nivel del periodonto son notorios. La necrosis pulpar sí que se asocia frecuentemente con inflamación del tejido periodontal, compartiendo mecanismos microbiológicos y etiológicos similares. Según la naturaleza de la microflora y la capacidad del huésped para resistir la infección, pueden generarse formase agudas (absceso agudo) y crónicas (reacción inflamatoria crónica) en cualquier sitio donde existe comunicación directa con la cámara pulpar. Una entidad puede evolucionar a la otra y, en ocasiones, puede ocurrir una transformación cística. Las lesiones pulpares van a poder afectar al periodonto a través de dos rutas principales (5):

1. Canales laterales. Las lesiones en el periodonto a través de estas vías de comunicación no es muy frecuente, pero hay que tenerlo en cuenta. Los productos bacterianos e inflamatorios, pueden causar lesiones en la zona lateral de la raíz y a nivel de las furcas en dientes multirradiculares.

2. Ápice. Se establece una lesión alrededor del ápice dentario. El absceso endodóntico sigue una de estas dos rutas:

- El proceso supurativo genera una fístula a lo largo del espacio del ligamento periodontal que se abre hacia el surco/bolsa periodontal, lo que lle- 
va a un aumento de la profundidad de sondaje (PS) en un único punto alrededor del diente o en la zona de la furca en dientes multirradiculares.

- El absceso periapical puede perforar el hueso cortical cerca del ápice y separar el tejido blando (periostio incluido) de la superficie del hueso y drenar hacia el surco/bolsa periodontal. Suele verse en vestibular y la sonda no penetra en el espacio del ligamento periodontal.

En ambos casos nos encontramos con una lesión endodóntica, con lo que curaran al realizar una endodoncia correcta, sin necesidad en un principio de terapia periodontal adicional.

\section{INFLUENCIA DEL TRATAMIENTO ENDODÓNTICO SOBRE EL PERIODONTO}

Una vez que hemos visto como las lesiones a nivel de la pulpa pueden afectar el periodonto en distintas porciones del mismo, es importante conocer el impacto que puede tener el tratamiento endodóntico y las medidas que usamos en el mismo.

Así, nos encontramos con que el tratamiento endodóntico puede producir lesiones inflamatorias en el periodonto por una irritación mecánico y/o química. Tenemos el caso de daño periodontal por los líquidos de irrigación, por tratamientos endodónticos defectuosos, por perforaciones radiculares al preparar el lecho de los pernos, etc.

Dentro de este apartado caben destacar las perforaciones de raíz y las fracturas verticales:

1. Las perforaciones se pueden dar en las paredes laterales de la raíz o en el suelo de la cámara pulpar en dientes multirradiculares. En el lugar de la perforación, la reacción inflamatoria puede dar lugar a una bolsa periodontal, si ésta esta localizada a nivel marginal.

2. Las fracturas verticales a día de hoy continúan siendo para el clínico desconocidas en muchos aspectos diagnósticos y de tratamiento. Dentro de los signos clínicos para poder orientar al odontólogo destacan una historia larga de dolor leve, con infecciones repetidas o con dolor a la masticación, la aparición de varios tractos sinuosos en el mismo diente, la aparición de tumefacción gingival a mitad de camino en la raíz, el descementado repentino de un perno antiguo y, sobretodo, la aparición de una bolsa periodontal estrecha, profunda y ais- lada. Entre los signos radiográficos se encuentra la visualización de la separación de los fragmentos radiculares, líneas de fractura a lo largo de la raíz o sobre o junto al relleno radicular, espacio adyacente a un poste, imágenes duplicadas, signos radiopacos, etc. Respecto al tratamiento, suelen ser casos que guardan un mal pronóstico y en la mayoría de los casos la extracción se convierte en la única opción posible. Si la fractura es incompleta en los dientes unirradiculares se podría utilizar el cemento de vidrio-ionómero o agregado trióxido mineral (MTA). En los multirradiculares el tratamiento de elección sería la amputación de la raíz afectada (6).

\section{INFLUENCIA DE LAS REABSORCIONES RADICULARES EXTERNAS}

La mayoría de los dientes muestran signos de reabsorción radicular activa o cicatrizada. Los traumas que sufren a diario los dientes, como son pequeños contactos indeseables durante la función, bruxismo, obturaciones altas, etc., pueden dañar el periodonto de manera localizada, desencadenando el inicio del fenómeno de reabsorción radicular. El tratamiento ortodóntico también puede conllevar a este fenómeno si se emplean fuerzas excesivas.

En general, los procesos de reabsorción externa de las raíces suelen avanzar sin síntomas clínicos y sin causar defectos periodontales que pudieran malinterpretarse como enfermedad periodontal o endodóntica. Sin embargo, en sus estadios avanzados podrían afectar al surco gingival y generar un absceso periodontal.

\section{INFLUENCIA DE LA ENFERMEDAD PERIODONTAL EN LA CONDICIÓN PULPAR}

Existen tres vías a través de las cuales la placa bacteriana que se acumula en las raíces de los dientes periodontales, puede afectar al estado de la pulpa: los conductos laterales expuestos, los forámenes apicales y furcales y los túbulos dentinarios. Sin embargo, lo normal es que haya muy pocas vías abiertas en los dientes afectados periodontalmente y, por otro lado, la pulpa es capaz de soportar elementos nocivos liberados por la lesión del periodonto mientras el aporte sanguíneo a través del foramen apical permanezca intacto. De este modo, Bergenholtz y Lindhe (1978) estudiaron perros a los que les inducían una enfermedad periodontal con una pérdida ósea de alrededor del 30-40\%, observando que en el 70\% de los casos, 
no se producía ninguna alteración en la pulpa. Así, la degradación de la pulpa no se produciría hasta que la enfermedad periodontal llegara a un estado terminal.

\section{INFLUENCIA DEL TRATAMIENTO PERIODONTAL SOBRE LA PULPA}

Se han llevado a cabo numerosos estudios en los que se ha tratado de investigar el efecto del tratamiento periodontal sobre el estado pulpar. Por un lado, los resultados de estudios clínicos y animales muestran que el raspado y alisado radicular (RAR) no suele afectar al estado pulpar, aunque pueden ocurrir pequeñas alteraciones inflamatorias adyacentes a la zona instrumentada, las cuales suelen ser seguidas por un proceso de reparación. Por otro lado, resulta interesante resaltar en este apartado la aparición de hipersensibilidad de la dentina radicular tras los procedimientos de tartrectomía y alisado radicular de la terapia periodontal (7).

\section{DIAGNÓSTICO DIFERENCIAL DE LASS LESIONES ENDO- PERIODONTALES}

Cuando analizamos los síntomas clínicos y los hallazgos radiográficos, muchas veces nos encontramos dificultades a la hora de saber si un diente tienen un problema periodontal o en su pulpa. La principal medida diagnóstica que tenemos para distinguir si una lesión es de origen endodóntico o periodontal es la prueba de vitalidad pulpar, que podemos llevar a cabo con un pulpo vitalómetro o con cloruro de etilo. Siempre habrá que tener en cuenta los falsos positivos y los falsos negativos de la técnica que empleemos para comprobar esa vitalidad. Los problemas surgirán cuando exista una lesión combinada, en la que haya que establecer cual es la lesión primaria, puesto que modificaremos nuestro tratamiento para conseguir el mejor pronóstico posible, a pesar de que este suele estar comprometido. (Tabla 1).

\begin{tabular}{|ccc|}
\hline & TABLA 1 & \\
\hline Etiología & Vitalidad & Tratamiento \\
\hline Endodóncica & - & Endodoncia \\
Periodontal & + & Tto. periodontal \\
Endo-periodontal & - & $1^{\circ}$ Endodoncia- \\
& & $2^{\circ}$ Tto. perio. \\
\hline
\end{tabular}

El pronóstico para la reparación del aparato de inserción parece ser favorable cuanto más amplia sea la parte de la lesión causada por la infección del conducto radicular, aunque clínicamente no es posible determinar en qué medida cada uno de los dos problemas afectó a los tejidos de sostén, por lo que lo primero sería realizar la endodoncia y tras un periodo de observación realizar si fuera necesario el tratamiento periodontal. Si tenemos un diente vital lo primero es raspar si nos encontramos con una lesión a nivel marginal. En el caso de que nos encontremos ante un diente no vital realizaremos la endodoncia y observaremos la respuesta, puesto que la capacidad de regeneración de los tejidos destruidos por una afectación pulpar es mucho mayor que cuando ésta se produce por causas periodontales. No siempre es fácil determinar si una lesión es combinada, por ello el tratamiento periodontal se reservará para el momento en que se empiece a observar la respuesta del tratamiento endodóntico.

\section{DEFORMIDADESY/O CONDICIONES DESARROLLADAS O ADQUIRIDAS}

En la clasificación de Armitage de 1999, se reconoce un apartado que engloba numerosas condiciones que pueden alterar el periodonto. Lo divide en cuatro subapartados que se van a explicar a continuación (1).

\section{FACTORES DENTALES LOCALIZADOS QUE MODIFICAN O PREDISPONEN A ENFERMEDAD GINGIVAL O PERIODONTAL INDUCIDA POR PLACA}

1. Factores dentarios anatómicos.

2. Restauraciones dentales.

3. Fracturas radiculares.

4. Reabsorción radicular cervical y perlas de esmalte.

1. Anatomía dental: Existen varios factores relacionados con la estructura dental, tales como: perlas del esmalte y lágrimas de cemento, surcos de desarrollo linguales, fracturas radiculares, reabsorciones cervicales de la raíz, puntos de contacto abiertos... son factores primarios locales que influyen en la acumulación de placa bacteriana por las complicaciones en la higiene oral, así como en la maduración y calcificación de la misma. Dado que el paciente tendrá problemas para su limpieza, ésta tendrá que ser completada por un profesional.

2. Materiales de restauración y Restauraciones desadaptadas y/o desbordantes: A nivel subgin- 
gival (bordes marginales, coronas e inlays) van a afectar a la salud periodontal de dos maneras:

- Coincide con que son áreas de difícil acceso, que se asocian a placa más que otras zonas sin restaurar o en zonas que se han restaurado correctamente.

- Favorecen el acúmulo y la maduración de la placa, variando la flora y provocando que ésa sea más patógena.

La afectación del tejido periodontal puede producirse por:

- Realización de preparaciones

- Uso de materiales cuyos componentes irritan los tejidos.

- Propiedades físicas y químicas de las restauraciones, que pueden provocar la retención de placa bacteriana.

3. Fracturas radiculares: Habrá que valorar en primer lugar si son horizontales o verticales. En el caso de las primeras el pronóstico mejora si éstas se producen en el tercio coronal del diente, mientras que según descendemos, esté empeora drásticamente. Sin embargo, las fracturas verticales tienen mal pronóstico desde el principio y suelen requerir la extracción del diente o de la raíz afectada, salvo que se produzcan a nivel coronal y sean incompletas o fisuras, lo que nos permite intentar hacer un sellado de las mismas.

4. Reabsorciones radiculares a nivel cervical deben ser abordadas con el tratamiento restaurador pertinente, según el grado de las mismas (1).

\section{DEFORMIDADES MUCOGINGIVALES Y CONDICIONES ALREDEDOR DE LOS DIENTES}

1. Recesión de tejido blando gingival.

a. Superficie vestibular o lingual.

b. Interproximal (papilar).

2. Ausencia de encía queratinizada.

3. Profundidad vestibular disminuida.

4. Posición aberrante músculo/frenillo.

5. Exceso gingival.

a. Pseudobolsa.

b. Margen gingival inconsistente.

c. Excesivo margen gingival.

d. Agrandamiento gingival.

6. Alteración del color.

1. La recesión gingival es el desplazamiento del margen de tejidos blandos hacia apical de la línea amelo-cementaria (LAC) con exposición de la superficie radicular. Dentro de estas condiciones cabe distinguir que existen unos factores desencadenantes como son el cepillado traumático y la enfermedad periodontal, y otros factores predisponentes, como son un biotipo periodontal fino o dehiscencias radiculares.

Miller propone, en 1985, una clasificación en la que tiene en cuenta el tipo de recesión y la predictibilidad de cobertura de la misma (8):

- Clase I: Recesión de tejido marginal que no sobrepasa la línea mucogingival. No hay pérdida de hueso o tejido blando interdentario. El recubrimiento total de la recesión se puede conseguir en un $100 \%$ de los casos.

- Clase II: Recesión de tejido marginal que sobrepasa la línea mucogingival o va más allá. No hay pérdida de hueso o tejido blando interdentario. El recubrimiento total de la recesión se puede conseguir en un $100 \%$ de los casos.

- Clase III: Recesión del tejido marginal que sobrepasa la línea mucogingival o va más allá. La pérdida de hueso o tejido blando interdentario es apical al LAC, pero coronaria a la extensión apical de la recesión de tejido marginal. También incluye la malposición dental. El recubrimiento al $100 \%$ no es predecible.

- Clase IV: recesión de tejido marginal que sobrepasa la línea mucogingival. La pérdida de hueso interdentario se extiende a un nivel apical a la extensión de la recesión del tejido marginal. También incluye la malposición dental severa. No se puede conseguir un recubrimiento total.

Por otro lado, existen varios factores pueden contribuir a la pérdida de altura de la paila y la formación de los antiestéticos "triángulos negros" entre los dientes. La causa más frecuente en el adulto es la pérdida de sostén periodontal debido a la enfermedad periodontal. Nordland y Tarnow (1998) proponen una clasificación de la altura de la papila interdentaria que incluye los siguientes apartados (8):

- Normal: la papila interdental ocupa todo el espacio de la tronera por apical del punto o área de contacto interdental.

- Clase I: la cima de la papila interdental se sitúa entre el punto de contacto interdental y el nivel de la LAC en la superficie proximal del diente.

- Clase II: la cima de la papila interdental se sitúa a nivel de la LAC o por apical de esta en la superficie proximal, pero en vestibular se ubica hacia coronario de la LAC.

- Clase III: la cima de la papila interdental se ubica a nivel de la LAC o por apical de ésta en V.

$\mathrm{El}$ tratamiento de las recesiones gingivales ha sido un campo muy estudiado dentro de la periodoncia y existen numerosas opciones terapéuticas, que he- 
mos de conocer bien para saber que técnica es más correcta para cada caso individual. Las causas de tratamiento más frecuentes son por estética, hipersensibilidad radicular y para facilitar el control de la placa bacteriana. Dentro del amplio abanico de posibilidades terapéuticas, caben destacar (9):

- Injertos libres de encía o de tejido conjuntivo.

- Colgajos pediculados: coronales o laterales.

- Combinaciones de técnicas.

- Regeneración (ya no se usa).

En el caso del tratamiento de la pérdida de papilas interdentales, Tarnow (1992) propone que hay que evaluar:

1) La distancia vertical entre la cresta ósea y el punto apical del área de contacto entre las coronas.

2) La altura del tejido blando en el área interdental. Si la distancia cresta ósea-punto de contacto es $=5$ $\mathrm{mm}$ y la altura de la papila no supera los $4 \mathrm{~mm}$, puede justificarse una intervención quirúrgica para aumentar el volumen de la papila. Pero si el punto de contacto está situado a más de $5 \mathrm{~mm}$ de la cresta ósea, por causa de una pérdida de sostén periodontal y/o de una relación de contacto interdental inadecuada, hay que seleccionar recursos para alargar hacia apical el área de contacto entre los dientes en vez de intervenir quirúrgicamente. Si la causa de pérdida de altura de la papila es debida a una lesión en los tejidos blandos por utilizar inadecuadamente productos para la higiene interdental, lo primero a hacer será cesar en la utilización de tales productos para permitir la recuperación de los tejidos.

2. La ausencia de encía queratinizada ha sido un tema que ha originado mucha controversia a lo largo de la literatura periodontal. Antiguamente prevalecía el concepto de que si había una banda estrecha de encía, ésta no era capaz de proteger al periodonto de las lesiones causadas 'por fuerzas de fricción generadas durante la masticación. A su vez se pensaba que esta situación favorecía el acúmulo de placa subgingival por la falta de unión de los tejidos blandos al diente, y con ello, la pérdida de inserción y la aparición de recesiones, además de impedir un correcto control de placa personal. La tendencia actual ha cambiado, puesto que se piensa que no es tan crítica como se pensaba, la cantidad de encía queratinizada e insertada. Así, caben destacar los estudios de Wennström y Lindhe (1983) o de Dorfman y cols. (1980), quienes demostraron que la cantidad de encía insertada no condicionaba la cantidad de inflamación, si no que ésta venía determinada por el grado de higiene oral. Lo importante es valorar cada caso de manera individual y ver si la cantidad de encía queratinizada es adecuada o inadecuada para cada paciente. En casos en los que se vayan a mover dientes ortodóncicamente hacia vestibular, en que vayamos a realizar restauraciones subgingivales o en los que el paciente se encuentre incómodo, será aconsejable realizar una técnica de aumento de encía queratinizada $(10,11)$.

Contamos con técnicas mocogingivales que nos permiten crear encía queratinizada, aunque estas técnicas deben ser reservadas para casos en los que la limpieza personal se vea dificultada o cuando vamos a realizar una restauración subgingival, aunque este tema está en controversia.

3. Profundidad vestibular disminuida. Al igual que ocurría con la cantidad de encía queratinizada, antes se pensaba que había que tener una profundidad vestibular mínima, con lo que numerosos pacientes eran sometidos a cirugías de aumento del fondo del vestíbulo, con el fin de evitar la impactación de las partículas alimenticias en los tejidos periodontales. Actualmente se ha restado importancia a esta situación y no se suele hacer nada, salvo casos en los que la poca altura del vestíbulo pueda favorecer la aparición de recesiones por la proximidad de los músculos a la encía, en cuyo caso se aconseja liberar esa zona muscular y llevar el tejido a una posición más apical con el fin de tratar de aumentar la altura del vestíbulo.

4. Frenillos aberrante. Los frenillos labiales son pliegues en forma de hoz que hacen la mucosa labial y yugal en su unión con la encía. Están compuestos por tejido conjuntivo laxo, con pocos vasos sanguíneos y carentes de fibras musculares. Pueden sufrir anomalías, tanto por el tamaño, forma, como por el lugar de inserción en la encía. La norma establece que el frenillo labial superior se una a $4,4 \mathrm{~mm}$ del margen gingival de los dientes superiores y a 5,6 $\mathrm{mm}$ del margen gingival de los dientes inferiores. Si esta distancia se ve disminuida puede dar lugar a problemas. Por otro lado, un frenillo grueso e hipertrófico puede modificar nuestro plan de tratamiento.

Entre los problemas que nos podemos encontrar derivados de una mala posición o forma del frenillo destacamos: diastemas y rotación en los dientes, movimiento de labios disminuido, dificultades en la fonación, pueden favorecer la formación de recesiones gingivales, etc. Por ello, ante estos casos, se recomienda una extirpación de los frenillos, para lo que disponemos de distintas técnicas quirúrgicas. 
5. Exceso gingival. El exceso gingival puede venir determinado por distintos aspectos que trataremos a continuación y hemos de saber reconocerlos para aplicar el tratamiento pertinente en cada caso. El resultado suele ser un aumento del volumen gingival y un aspecto de coronas clínicas más cortas de lo normal. Hemos de conocer las siguiente condiciones:

- Pseudobolsa: Se trata de una encía inflamada, que si sondamos, tiene una PS mayor de $3 \mathrm{~mm}$. La diferencia con la EP es que en este caso no hay pérdida de inserción y el aumento de la PS se debe exclusivamente al aumento de volumen que sufre la encía por la inflamación. Suele presentar un aspecto edematoso y enrojecido, característica de la gingivitis. Este sobrecrecimiento gingival es fácilmente abordable, pues con una buena tartrectomía, junto a la eliminación de los factores que puedan favorecer el acúmulo de placa, podemos erradicarlas y conseguir que la encía vuelva a su estado previo.

- Márgenes gingivales: La posición de los márgenes gingivales es uno de los principales aspectos estéticos que hemos de tener en cuenta en nuestro plan de tratamiento, puesto que son muy influyentes en la estética. Las alteraciones en los mismos se pueden deber a numerosas causas, como son el propio progreso de la EP, recesiones gingivales localizadas, apiñamientos dentarios, etc. Por un lado hemos de analizar su posición apico-coronal y mesio-distal, y por el otro el volumen, pues este último puede estar afectado y producir alteraciones en la estética.

La norma estética establece que, teniendo en cuenta el tamaño ideal de las coronas de los dientes, los márgenes de los incisivos centrales superiores deben estar a la misma altura entre sí, con el cenit ligeramente desplazado hacia distal. El margen de los laterales debe coincidir entre sí y estar aproximadamente $1 \mathrm{~mm}$ más a apical que el margen de los laterales. En el caso de los caninos, los márgenes deben coincidir con el de los laterales o estar ligeramente más hacia coronal. Esto es lo que establece la norma, y contamos con numerosas alternativas para poder corregir defectos de los márgenes, entre los que destacamos: cirugía mucogingival (injertos y colgajos pediculados), manejo de los márgenes gingivales con ortodoncia, control con nuestras restauraciones, gingivectomías (a bisel interno y externo), alargamiento coronario, etc. En cualquiera de los casos, se tienen que intentar conseguir una correcta distribución armónica de los mismos.
- Agrandamiento gingival: El aumento del volumen de encía se puede producir por otras causas que no sean de tipo inflamatorio. Existen numerosos medicamentos, como son los antiepilépticos, bloqueantes del calcio, ciclosporinas, etc., que entre sus mecanismos de acción destaca la capacidad de producir una hipertrofia de la encía, que aumenta de volumen y suele adquirir un aspecto fibrótico. No suele guardar una correlación con el aumento de placa, aunque ambas se pueden dar a la ver, puesto que la hipertrofia gingival puede dificultar la eliminación de la placa, lo cual puede hacer que el tejido se inflame y crezca más. Ante estos casos lo primero es ver el medicamento que lo está causando, con el fin de tratar de sustituirlo o de bajar la dosis del mismo (siempre consultando con el médico del paciente que le haya recetado dichos medicamentos). Además, siempre disponemos de la cirugía para eliminar el exceso de encía, aunque si no se modifica el régimen del medicamento el proceso tiende a recidivar

- Erupción pasiva alterada: Por último, en este apartado, es importante tener en cuenta la erupción pasiva, pues una alteración de la mis a nos puede traer consigo alteraciones estéticas en nuestros márgenes gingivales y coronas clínicas cortas (12).

1. La erupción activa se define como el movimiento hacia oclusal de un diente desde que emerge por la encía. Esta fase termina cuando el diente entra en contacto con los dientes opuestos. La erupción pasiva se caracteriza por la migración apical de la unión dentogingival, de tal forma que la corona clínica va aumentando de tamaño a medida que la inserción epitelial migra apicalmente.

2. La erupción pasiva alterada aparece cuando el margen de la encía queda situado más incisal u oclusalmente en el diente adulto y no se acerca al LAC. Coslet y cols. en 1977 clasifican la erupción pasiva teniendo en cuenta 2 aspectos: la cantidad de encía queratinizada y la altura d la cresta ósea:

- Tipo 1: margen gingival incisal u oclusal al LAC y hay una amplia banda de encía desde el margen gingival a la unión mucogingival. Dicha unión mucogingival es apical a la cresta alveolar.

- Tipo 2: dimensión gingival de anchura normal, localizándose toda la encía en la corona anatómica y la unión mucogingival se localiza a nivel del LAC. 
- Subgrupos A: la distancia cresta alveolarLAC es de 1,50-2,0 mm (distancia normal), permitiendo la inserción de las fibras gingivales en el cemento.

- Subgrupo B: la cresta alveolar está a nivel del LAC (esto se observa frecuentemente en la dentición mixta). El tipo $1 \mathrm{~B}$ es el más frecuente.(Figura 1).

Hay que tener muy presente el concepto de alargamiento coronario, espacio biológico, ferrule... El alargamiento coronario comprende una serie de técnicas quirúrgicas que se llevan a cabo en los casos de erupción dental pasiva alterada o cuando hay necesidad de exponer tejido dentario sano en el caso de lesiones cariosas y líneas de fractura subgingivales, entre otras. El concepto más importante a tener en cuenta es el de la anchura biológica, espacio biológico o unión dentogingival ,que fue definida por Gargiulo en 1961 y Vacek en 1994 como la suma de la dimensión de la unión del conectivo con la raíz con la dimensión de la inserción epitelial. En realidad, estas dimensiones no son fijas, ya que varían entre individuos y entre los distintos dientes. Los valores medios obtenidos tras varios estudios son (13):

-Longitud de la unión conectiva: 1,07 mm.

- Longitud de la inserción epitelial: 0,97 mm.

- Junto a estos valores hay que considerar la longitud normal del surco gingival: 0,69 mm.

Para la restauración de un diente que ha perdido parte de su estructura debido a fractura, caries, o desgaste oclusal, se debe valor la cantidad de tejido sano remanente supracrestal y dónde vamos a situar los márgenes de nuestra futura restauración. Es siempre conveniente que los márgenes nunca invadan la anchura biológica y que exista una altura suficiente de diente sano expuesto (ferrule) para evitar futuras fracturas o la descementación de pernos o coronas. Así, teniendo en cuenta las dimen-

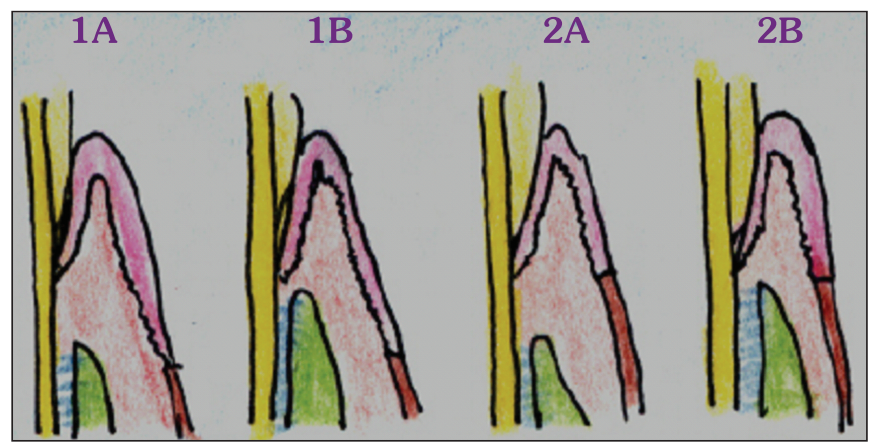

Fig. 1: Rx de paciente 1 . siones de la anchura biológica debemos situar los márgenes de las restauraciones a $3 \mathrm{~mm}$ aproximadamente desde la cresta ósea, sino, aumenta el riesgo de aparición de caries secundarias debido a una peor limpieza a nivel subgingival, un mayor acúmulo de placa favorecido por el gap de la interfase corona-diente, con la consecuente inflamación del periodonto, aumento de la profundidad de sondaje y, en algunos casos, recesión gingival. Entre las técnicas terapéuticas encontramos: extrusión ortodóncica, extrusión quirúrgica y técnicas quirúrgicas de alargamiento coronario.

Según el tipo de erupción pasiva que presente el paciente, realizaremos un tratamiento distinto (14):

1. A: Gingivectomía a bisel externo

B: Gingivectomía con remodelado óseo

2. A: Colgajo a bisel interno sin remodelado óseo.

B: Colgajo a bisel interno con remodelado óseo.

6. Las alteraciones del color de la encía se dan cuando el color de esta se aleja del rosa coral característico de las misma. Estas alteraciones se pueden deber al acúmulo de melanina, como ocurre en las melanoplaquias que se dan principalmente en la raza negra, por un aspecto inflamado de la misma, que trae consigo un color rojo con aspecto edematoso o por una tinción de amalgama u otro metal. En cualquier caso se debe hacer el diagnóstico diferencial con las lesiones orales que traigan consigo un cambio en la coloración de los tejidos gingivales y de las mucosas orales. Para eliminar las pigmentaciones contamos con la microabrasión o el láser. En cualquier caso, el paciente suele ser el que demanda este tratamiento estético, pues no constituye ningún problema patológico.

\section{DEFORMIDADES Y CONDICIONES MUCOGINGIVALES SOBRE CRESTAS EDÉNTULAS}

1. Deficiencia horizontal y/o vertical de cresta ósea.

2. Ausencia de tejido queratinizado/encía.

3. Agrandamiento tejido blando/gingival.

4. Posición aberrante del frenillo o muscular.

5. Profundidad vestibular disminuida.

6. Alteración del color.

Las deformidades y condiciones mucogingivales que acontecen sobre crestas edéntulas son bastante semejantes que las que tienen lugar en los dientes (15).

1. La cresta ósea puede sufrir deformaciones por causas diversas a lo largo de la vida, como son defecto 
de nacimiento, traumatismos, tumores, extracciones dentarias, enfermedad periodontal avanzada o formación de abscesos. Esto nos puede comprometer la estética, el soporte de prótesis mucosoportadas o la colocación de implantes. Existe una clasificación, propuesta por Seibert (1983), que describe como se producen las pérdidas de los tejidos crestales.

- Clase I: Pérdida de tejido en dirección V-L, existiendo una altura normal en dirección apico-coronaria.

- Clase II: Pérdida de tejido en dirección apico-coronaria con ancho normal en dirección V-L.

- Clase III: combinación de las clases I y II; es decir, pérdida de altura y espesor.

Esta circunstancia nos puede llevar a tener que incluir en el plan de tratamiento la necesidad de realizar un aumento del volumen de la cresta, tanto en sentido vestíbulo-lingual como en apico-coronal.

3. La ausencia de tejido queratinizado tiene las mismas connotaciones que en el caso de que haya dientes, puesto que mientras haya una correcta higiene oral, no habrá inflamación, independientemente de haber o no encía insertada. En cuanto a la cantidad de encía insertada alrededor de los implantes, también ha habido mucha controversia y ha sido un tema ampliamente estudiado. Como ocurre con los dientes, ante ausencia de placa, no habrá inflamación, aunque esto suele ser más difícil de lograr con los implantes, pues la higiene se ve dificultada. Por eso es recomendable partir de una buena encía queratinizada, la cual podemos conseguir con distintas técnicas mucogingivales, cuya descripción no es tema de esta revisión.

4. El agrandamiento gingival, los frenillos aberrantes y la profundidad vestibular disminuida tiene las mismas implicaciones que para cuando hay dientes. Un exceso de tejido o unos frenillos prominentes nos puede comprometer el soporte de nuestras prótesis removibles mucosoportadas y la cirugía preprotésica puede ser necesaria. En crestas en las que se vayan a poner implantes habrá que tenerlos en cuenta, pues habrá que conseguir una estética y un perfil biológico deseables.

5. Las alteraciones en el color sólo tendrán importancia cuando vayamos a realizar prótesis implantosoportadas o dentosoportadas sin acrílico o cerámica que nos enmascaren el color de la encía. En los casos en los que supongan un compromiso estético se tendrán en cuenta los mismos aspectos que para las alteraciones del color de los tejidos alrededor de los dientes.

\section{TRAUMa OCLUSAL}

El trauma por oclusión comprende aquellas alteraciones patológicas o de adaptación que se producen en el periodonto como resultado de fuerzas indebidas producidas por los músculos masticatorios. También se pueden afectar la ATM, los músculos masticatorios y el tejido pulpar.

Existen dos tipos de trauma oclusal:

- Primario: es el daño de los tejidos provocado alrededor de un diente con periodonto de altura normal como resultado de fuerzas excesivas

- Secundario: es el daño provocado por las fuerzas oclusales en un periodonto de altura reducida como resultado de fuerzas normales

Las alteraciones que se producen en ambas formas son las mismas, pero en un periodonto reducido, incluso fuerzas comparativamente pequeñas pueden producir lesiones traumáticas. Algunos de los signos clínicos con los que nos podemos encontrar son la movilidad dental aumentada, la movilidad progresiva o los defectos angulares (no son patognomónicos del trauma oclusal).

En este aspecto cabe destacar el estudio de Svanberg y Lindhe (1973), en el que estudian las fuerzas traumáticas oscilantes en las distintas situaciones clínicas ante las que nos podemos encontrar (16):

- Periodonto sano con altura normal: Se produce un aumento de la movilidad por un ensanchamiento del LP, que deja de aumentar cuando el diente se adapta a la situación. No hay pérdida de tejidos periodontales.

- Periodonto sano con altura reducida: El diente se hace hipermóvil al adaptarse su LP al trauma. No se produce pérdida adicional de soporte periodontal y la respuesta es similar que al diente sano con altura normal.

- Periodonto infectado por placa: Ocurre lo mismo que antes pero además pueden aparecer defectos angulares. Si el diente es capaz de adaptarse a las fuerzas la movilidad progresiva cesa, así como la reabsorción ósea, pero no así los defectos angulares ni la movilidad aumentada. Si el diente no es capaz de adaptarse al trauma, la movilidad progresiva 
persiste, así como la reabsorción ósea y la formación de defectos angulares.

A nivel de la clínica lo que nos vamos a encontrar es una movilidad dental aumentada, que debe distinguirse de la movilidad progresiva. Se debe realizar el diagnóstico diferencial entre las distintas situaciones clínicas, pues según tengamos un caso u otro realizaremos un tratamiento determinado. Ante casos de un aumento de movilidad hay que hacer la siguiente distinción y protocolo de actuación (17):

- Altura normal de hueso

- > Anchura LP AJUSTE OCLUSAL

- Altura reducida de hueso

- > Anchura LP

1. Diente sano AJUSTE OCLUSAL

2. Diente enfermo TTO. PERIODONTAL + AJUSTE OCLUSAL

3. Mov. progresiva TTO. PERIODONTAL + FERULIZACIÓN

- Anchura de LP normal

1. Mala función FERULIZACIÓN

2. Buena función NADA

\section{CONCLUSIONES}

- Los resultados de los estudios llevados a cabo en humanos y en animales muestran que el trauma oclusal sobre un diente con periodonto sano, no produce la formación de bolsas ni la pérdida de inserción del tejido conectivo.

- El trauma oclusal produce una reabsorción fisiológica de hueso alveolar que trae consigo aumento de la movilidad, ya sea transitoria o permanente.

- El trauma oclusal sobre dientes con EP progresiva puede aumentar el progreso del proceso de destrucción periodontal.

\section{SUMMIARY}

Introduction: In the last workshop in periodontics of the American Association of Periodontology in 1999, different groups of lesions were added because of it high prevalence and the impossibility of classifying them in another group, in orther to perform a correct differential diagnose. The objectives of this paper are: a) To know the impact of endo-perio lesions to make a correct differential diagnose and the best treatment strategy; b) To know the conditions and malformations that can appear in the periodontal tissues.

Materials, Methods and Results: For the preparation of this work, 17 articles published in international and national scientific journals have been analyzed. The MEDLINE and Cochrane databases have been used to make the search.

\section{KEY WORDS}

WorldWorkshop, endo-perio lesions, periodontitis, gingival recession, queratinized gingiva, trauma from occlusion.

\section{BIBLIOGRAFÍA}

1. Armitage G. Development of a classification system for periodontal diseases and conditions. Annals of periodontology/the American Academy of Periodontology. 1999;Dec;4(1):1-6.

2. Brook. O. 1999 International International Workshop for a Classification of Periodontal Diseases and Conditions. Papers. Annals of periodontology/the American Academy of Periodontology. 1999;Dec;4(1:i): 1-112.

3. Lindhe Jan KT, Lang Niklaus P. Periodontología clínica e implantología odontológica. $4^{a}$ edición.Buenos Aires. Editorial: editorial médica panamericana. 2005.

4. Bascones AM. Periodoncia clínica e implantología oral. 2000.

5. Nair PN. Pathogenesis of apical periodontitis and the causes of endodontic failures. Crit Rev Oral Biol Med. $2004 ; 15(6): 348-81$.

6. Moule AJ, Kahler B. Diagnosis and management of teeth with vertical root fractures. Aust Dent J. 1999 Jun;44(2): 75-87.

7. Von Troil B, Needleman I, Sanz M. A systematic review of the prevalence of root sensitivity following periodontal therapy. J Clin Periodontol. 2002;29 Suppl 3:173-7; discussion 95-6.

8. Hall W. The curren status of mucogingival problems and their therapy. J Periodontol. 1981,sep 52(9): 569-75.

9. Dorfman, HS, Kennedy,J.E. \& Bird, WC. Longitudinal evaluation of free gingival grafts. A tour year report. Journal of periodontology (1982);53: 349-52.

10. Wenström, J.L. \& Lindhe, J. The role of attached gingival for maintenaince of periodontal health. Healing 
following excisional and grafting procedure in dogs. Journal of clinical periodontology 1983;10: 266-76.

11. Dorfman HS, Kennedy, JE, Bird WC. Longitudinal evaluation of free autogenous gingival grafts. Journal of Clin Periodontology. 1980;7:316-24.

12. Dolt A, Robbins W. Altered passive eruption: an etiology of short clinical crowns. Quintessence International 1997, 28(6):363-72.

13. Ferrús Cruz J, MEA, Mudarra Morante S, Vignoletti F, Alonso Sanz M, Zabalegui I. Alargamiento coronario: importancia clínica y técnicas. Gaceta Dental. 2006; n: 167 (febrero).

14. Levine R y McGuire M. The diagnosis and treatment of the gummy smile. Compend Dent educ 1997;18(8):757-64.
15. Dietrich T, Zunker P, Dietrich D, Bernimoulin JP. Apicomarginal defects in periradicular surgery: classification and diagnostic aspects. Oral Surg Oral Med Oral Pathol Oral Radiol Endod. 2002 Aug;94(2):233-9.

16. Svanberg, G \& Lindhe, J. Experimental tooth hipermovility in the tooth. A methodological study. Odontologisk Revy. 1973; 24:269-82.

17. Bernal G, Carvajal JC, Munoz-Viveros CA. A review of the clinical management of mobile teeth. J Contemp Dent Pract. 2002 Nov; 15;3(4):10-22.

\section{CORRESPONDENCIA}

Ignacio Sanz-Sánchez email: ignaciosanz@mac.com 